\title{
Educar para a tolerância na experiência da alteridade: a anterioridade do Outro que me interpela
}

\author{
Nilo Agostini*
}

Este texto é fruto de uma investigação teórica e busca traçar a imbricação ou até mesmo as mútuas transversalidades existentes entre educação, tolerância e alteridade. Reconhecemos existir na tolerância um desafio para a capacidade humana de "agir conscientemente sobre a realidade objetivada" (FREIRE, 2008, p. 29), tão fortemente marcada por situações de intolerância. Investigamos os passos que são anteriores à tolerância, ou seja, os fundamentos primeiros, tais como a experiência, a proximidade, a alteridade e a própria educação. Sem estes, o "educar para a tolerância" tornar-se-ia mais um tema distante da realidade, apenas mais um palavreado, sem a necessária criticidade, própria da mulher e do homem da práxis, na sua "ação e reflexão sobre o mundo" (FREIRE, 2008, p. 30).

Iniciaremos pela experiência que possui uma densidade toda especial. Sua aplicação no campo da educação é muito diversa. Segundo Larrosa (2011), importa buscar o seu "uso afiado e preciso", superando "um uso e abuso da palavra experiência em educação" (p. 4). Seguiremos enfatizando a proximidade e sua anterioridade, qual veritas prima, quando me coloco diante de um sujeito real no facea-face (DUSSEL, 1980, p. 142). Ao mesmo tempo, abordaremos a alteridade, como dinamismo que torna rica toda experiência, à medida que tira o indivíduo do seu casulo fechado e estéril e abre-o ao outro, diverso de si, tornando-o pessoa, um ser em relação, na partilha do mundo (AGOSTINI, 2010, p. 88-93). A educação, por sua vez, ocupa nossa atenção, à medida que ela identifica na tolerância uma urgência nas atuais práticas e discussões, vindo à tona, segundo Pinheiro (2010), "a necessidade de uma formação que insira a tolerância como fundamental no processo de educação" (p. 39).

\section{Antes de tudo, a experiência}

Para Larrosa (2011), a experiência é "isso que me passa"; "supõe, em primeiro lugar, um acontecimento ou, dito de outro modo, o passar de algo que não sou eu" (p. 5). Neste termo, identificase um "princípio de exterioridade", de tudo o "que não sou eu" ou de "outra coisa que eu", assim expressa: "outra coisa do que aquilo que eu digo, do que aquilo que eu sei, do que aquilo que eu sinto, do que aquilo que eu penso, do que eu antecipo, do que eu posso, do que eu quero" (p. 5).

Ainda para Larrosa (2011), na experiência, existe "algo outro, algo completamente outro, radicalmente outro" que vem, então, identificado como "princípio de alteridade", ou seja, que é "outra coisa que eu" (LARROSA, 2011, p. 6). Aí se expressa, igualmente, um "princípio de alienação", pois isso que me passa é "alheio a mim", ou seja,

não pode ser meu, não pode ser de minha propriedade, não pode estar previamente capturado ou previamente apropriado nem por minhas palavras, nem por minhas ideias, nem por meus sentimentos, nem por meu saber, nem por meu poder, nem por minha vontade, etc (LARROSA, 2011, p. 6).

Se a experiência é algo que me passa, mesmo que suponha um acontecimento exterior a mim, alheio a mim, o certo é que sou eu o lugar da experiência. O mesmo estudo de Larrosa (2011) identifica aí três princípios, o da subjetividade, o da reflexividade e o da transformação. Existe sempre uma experiência que é subjetiva, à medida que o sujeito é aberto, sensível e se ex-põe, sendo a experiência única, singular, particular, própria para cada sujeito. Nela, se vive um movimento de ida e volta, de saída e de retorno que afeta a mim, produz efeitos em mim (reflexividade). E, ao se ex-por, o sujeito se abre à própria transformação, quer de suas palavras e de suas ideias, quer de seus sentimentos e de suas representações, entre outras. Abre-se, outrossim, à travessia, contida no per da experiência, tendo a ver com passagem, caminho, viagem.

A experiência supõe, portanto, uma saída de si para outra coisa, um passo para outra coisa, para esse ex de que falamos antes, para esse isso de "isso que me passa". Mas, ao mesmo tempo, a experiência supõe também que algo passa desde o acontecimento para mim, que algo me vem ou me advém. Esse passo, além disso, é uma aventura e, portanto, tem algo de incerto, supõe um risco, um perigo. De fato, o verbo "experiência" ou "experimentar", o que seria "fazer uma experiência de algo" ou "padecer uma experiência com algo", se diz, em latim ex/periri. E desse periri vem, em castelhano, a palavra "perigo". Esse seria o primeiro sentido desse passar. $O$ que poderíamos chamar de "princípio de passagem” (LARROSA, 2011, p. 8).

Ser território de passagem toca a minha sensibilidade, deixa um vestígio, crava uma marca, desenha um rastro, produz uma ferida. A partir desta percepção, entrevemos que o sujeito não é, de per si,

\footnotetext{
*Endereço eletrônico: nilo.agostin@usf.edu.br
} 
ativo; antes, é passivo. Assim, a experiência tem um sentido passional, de um sujeito paciente, revelando um "princípio de paixão", no dizer de Larrosa (2011, p. 8).

\section{A proximidade e sua anterioridade}

A experiência, em sua expressão primigênia, é a da proximidade mãe-filho, proximidade alterativa, do "nascer em alguém e não em algo, do alimentar-se de alguém e não de algo" (Silva, 1998, p. 234), sendo esta a experiência primordial, anterior a toda origem. Na expressão de Dussel (1980), ela expressa "a anterioridade anterior a toda a anterioridade", assim descrita em seu texto:

Aproximar-se é surgir do além da origem do mundo. É um ato anárquico (se arché é a

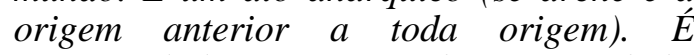
anterioridade anterior à toda anterioridade. Se o sistema ou o mundo é o anterior às coisas que habitam nele; se a responsabilidade pelo mundo do outro é anterior ao próprio mundo; aproximar-se à imediatez da proximidade é a anterioridade de toda anterioridade (DUSSEL, 1980, p. 23).

Para Silva (1998), "este ponto é importante para entender a dimensão ética da proximidade, pois, antes de ser, está o rosto do outro. Antes do mundo, está a face diante da face. E esta é a proximidade originária - o face-a-face" (p. 234). Descortina-se, assim, que o "estar junto ao outro, com o outro, revela que sua presença é sempre próxima" (SILVA, 1998, p. 233). Próxima como veritas prima, na presença junto a, antes mesmo de dizer qualquer palavra, desvelando-se, na nudez diante do outro, na fidelidade, na responsabilidade calada (DUSSEL, 1980, p. 142). Num filosofar situado, como o tem desenvolvido Enrique Dussel e o próprio Emmanuel Lévinas, coloco-me diante de um sujeito real que, no pobre, me "interpela a partir de seu rosto negado, de sua carnalidade ferida" e me provoca por uma " "posição de estar diante de' que seja autenticamente ética” (SILVA, 1998, p. 233).

O face-a-face é o que "dá consistência à ética e lhe confere realidade (...). Não existe o ser nele mesmo sem o dado referencial que o remete ao outro, no face-a-face" (AGOSTINI, 2010, p. 94, 95). O outro emerge como face, como rosto que me interpela, que me exige. À medida que vivo o face-aface, nasce o compromisso pelo outro, num ser pelo outro, mais do que com o Outro, o que me remete ao concreto diante do rosto do outro que é estar junto do face-a-face (LÉVINAS, 2014), sem cair no subterfúgio de meras palavras.

Bauman (1997), na esteira de Lévinas
(2014), afirma que "a filosofia primeira é uma ética", sublinhando que a "ética vem antes da ontologia", para arrematar que "o relacionamento moral vem antes do ser" (p. 85). Diz isso para enfatizar a condição do "face-a-face", num ascender acima do ser, sem balizar-se pela força na relação com o Outro, nem pelo dever. É diante do não-ser dos rostos negados, da carnalidade desfigurada, da face sem defesa que o Outro se me surge na sua autoridade. Não há força, não há resistência, apenas a nudez de uma face. Não há como ser com o Outro, senão ser pelo Outro, dando-me a mim mesmo como refém ao Outro. Enfim, "tomo a responsabilidade pelo Outro, (...) sem depender dos méritos do caso ou da qualidade do Outro (...). Minha responsabilidade, que constitui simultaneamente o Outro como a Face e eu como o eu moral, é incondicional" (BAUMAN, 1997, p. 88).

\section{A alteridade para além da totalidade domesticadora}

$\mathrm{O}$ modo de ser no mundo, na experiência e na proximidade, pode sofrer violência quando o outro não é tolerado em seu modo próprio de ser ou enquanto exterioridade e distinção. Costa (1998) nos diz que "violência significa aprisionar todos os entes, diferentes entre si, numa generalização que os condiciona e os condena a 'não poder deixar de ser', a 'não poder ser outro' e a 'não poder ser diferente", (p. 119). Partilhar o mundo na alteridade torna-se o desafio por excelência, constitui-se no coração que nos mantém vivos, garantindo vitalidade e real fecundidade ao viver (AGOSTINI, 2010, p. 88-93).

Toda forma de violência, como o faz a guerra e toda intolerância, "destrói a identidade e a possibilidade da alteridade de todos os que nela estiverem envolvidos" (COSTA, 1998, p. 97). Chega a ser uma violência ontológica que assume os contornos da totalidade e, enquanto tal, "dirige as pessoas, lhes infunde um sentido e significado, as faz agir e desempenhar papéis que não são os seus" (COSTA, 1998, p. 97).

Numa crítica à própria filosofia ocidental, Lévinas (1961) apresenta como os entes são presos a uma ordem objetiva no mundo quando dominados e/ou enquadrados em seu sentido e significado numa totalidade que se impõe.

A guerra não mostra a exterioridade nem um outro enquanto Outro; destrói a identidade do Mesmo. A face do ser que aparece na guerra se fixa no conceito de totalidade que domina a filosofia ocidental (LÉVINAS, 1961, p. 6).

Buscar prender o ser numa totalidade é reduzi-lo a uma caricatura; na verdade, ele excede, 
transcende a totalidade ao infinito. Existe no ser "uma excedência sempre exterior à totalidade", para além do jogo de cartas marcadas, para além de toda intolerância, além de toda guerra, captada por Lévinas (1961, p. 7) através do conceito de infinito.

Reconstituir a subjetividade $e \quad a$ intersubjetividade humanas a partir da ideia do infinito é fundar uma nova teoria (metafísica da alteridade, antropologia da alteridade, ética da alteridade) e uma nova ação (política da alteridade: justiça). A subjetividade eticamente constituída a partir do infinito como "ser para o Outro" funda a intersubjetividade e a socialidade capazes de fazer justiça ao ente que tem o modo de ser de um genuíno ser-humano, modo de ser e ente até agora caricaturizados na ontologia pela face violenta do ser que se decanta na totalidade (COSTA, 1998, p. 110-111).

Um modo especial de viver a alteridade reside na relação com o outro ser humano, do quão infinito é ele ante a ideia que o representa. À medida que me posto como "ser diante de", o rosto do "outro ser humano" apresenta-se e supera a ideia que eu tenho dele. "O face-a-face supera em originalidade e radicalidade as representações inteligidas e a ideia que se pode ter do infinito do 'ser humano' inteligido" (COSTA, 1998, p. 125).

O desafio que se apresenta é educar para a tolerância como ensino ou ser ensinado pela "recepção da ideia do infinito que é 'o Outro' e o rosto do Outro no face-a-face [...]; é receber uma lição sobre um conteúdo que vem de fora e que traz mais do que o 'eu' contém" (COSTA, 1998, p. 125).

\section{Educar para a tolerância}

A educação vem toda permeada pela necessidade do diálogo na relação inter-humana. $\mathrm{E}$ uma educação que seja ética implica a tolerância, alicerçada num encontro dialógico, sendo este seu primeiro passo. O diálogo inter-humano aparece como a condição para a construção de um lugar todo atravessado pela tolerância ante o pluralismo de valores, bem como face ao pluralismo de grupos e de interesses na sociedade. Este diálogo constitui-se no ponto de partida enquanto resposta à alteridade.

Este é um mover-se na ética, por excelência. Na explicitação de Alves e Ghiggi (2011), lemos:

A ética é a resposta à interpelação que o Outro me dirige, é uma resposta a posteriori, que sempre se dá em uma situação concreta, é uma resposta que nunca podemos estabelecer por antecipação e que não pode ser programada. Numa palavra, a ética é uma reposta sensivel e acolhedora do outro. (ALVES; GHIGGI, 2011, p. 252).

A ética, enquanto elemento constitutivo da ação educativa, tem sua real densidade quando permeada pela dinâmica da alteridade, enquanto "relação que nos impulsiona à atenção, ao cuidado, à hospitalidade e ao acolhimento responsivo de outrem" (ALVES;GHIGGI, 2011, p. 253).

Assim, a práxis dialógica abre o caminho para a superação de qualquer concepção bancária de educação ou de puro doutrinamento ou ainda de adestramento, numa relação que seria de opressão. Esta foi descrita por Freire (2014) nos seguintes temos:

O diálogo é este encontro dos homens, mediatizados pelo mundo, para pronunciálo, não se esgotando, portanto, na relação eu-tu. Esta é a razão por que não é possível o diálogo entre os que querem a pronúncia do mundo e os que não a querem; entre os que negam aos demais o direito de dizer a palavra e os que se acham negados deste direito. É preciso primeiro que os que assim se encontram negados no direito primordial de dizer a palavra reconquistem esse direito, proibindo que este assalto desumanizante continue (FREIRE, 2014, p. 109).

A relação dialógica e ética, toda alimentada pela alteridade, funda a educação, enquanto sua essência mesma, levando ao comprometimento ético pelo Outro, numa responsabilidade prévia ante o Outro, sendo este o "modo original" de transcender, de ver e de pensar "além" (LÉVINAS, 2002, p. 198).

No processo educativo, a formação para a tolerância torna-se fundamental. A relação dialógica e ética, permeada pela alteridade, cria as condições para que os membros da sociedade possam assumir a tolerância, à medida que compreendem e respeitam a diferença. Segundo Pinheiro (2010, p. 42-44), essa educação supõe o desafio de aprender a se colocar no lugar dos outros, respeitar o pluralismo, conviver com o diferente, decidir ser tolerante, enquanto desafios fundamentais à educação. Supõe igualmente, segundo proposta de Höffe (2003, p. 111), a aceitação da diferença como condição para um convívio civilizado com os outros, o assentimento espontâneo no reconhecimento do outro que tem igual valor, bem como a busca de consenso através do diálogo aberto no seio da sociedade pluralista.

Hoje, a percepção unitária de mundo não é mais possível. Passamos do uno ao múltiplo. Não temos uma única cultura como guarda-chuva ou como abrigo. Franklin (2010, p. 50-51) nos explica como "na atualidade vivenciamos uma 
multiplicidade de percepções díspares sobre o mundo e o humano", indicando que "agora nos centramos na diferença, no múltiplo, no outro". Já não temos mais um princípio comum e agregador como veiculado pela ideia de unidade metafísica grega. A própria razão, na acepção moderna, deixa hoje de ser um princípio agregador, capaz de sustentar um vértice comum.

A grande aposta reside na educação. Esta nos permite, segundo Franklin (2010, p. 55-59) formar o caráter do humano, numa educação essencialmente ética, apesar de imersos na multiplicidade ou na diversidade. Ela nos permite desenvolver uma cultura ética do ser humano, conscientes da importância da alteridade, no respeito de acordos sociais que buscam o equilíbrio entre a multiplicidade e a diversidade particular.

Ao afirmar a necessidade de "resgatar-se a si mesmo expandindo-se em humanidade", Franklin (2010) enfatiza a educação ética nos seguintes termos:

A educação ética necessita da direção das concepções de alteridade e diversidade para construir caminhos para o ato de educar. Esses caminhos podem, muitas vezes, se resumir a um único: buscar a humanidade no indivíduo. Pois, é no desenvolvimento de valores éticos que se apoia a manutenção do corpo social e da ação educativa (FRANKLIN, 2010, p. 58).

\section{Referências}

AGOSTINI, N. Ética: diálogo e compromisso. São Paulo: FTD, 2010.

ALVES, M. A.; GHIGGI, G. Da ética do diálogo à ética da alteridade - Por uma educação inter-humana. Educere et Educare, Cascavel, vol. 6, n ${ }^{\circ}$ 12, p. 251265, jul./dez 2011.

BAUMAN. Z. Ética pós-moderna. São Paulo:
Paulus, 1997.

COSTA, M. L. Lévinas: Uma introdução. Petrópolis: Vozes, 2000.

DUSSEL, E. Filosofia da Libertação. São Paulo: Loyola, 1980.

FRANKLIN, K. Educação e ética: O reconhecimento da alteridade na educação. In: GUÉRIOS, E.; STOLTZ, T. (Org.). Educação e Alteridade. São Carlos: EDUFSCar, 2010, p. 49-60.

FREIRE, P. Conscientização: Teoria e prática da libertação. Uma introdução ao pensamento de Paulo Freire. São Paulo: Centauro, 2008.

Pedagogia do oprimido. $37^{\mathrm{a}}$ ed. Rio de janeiro: Paz e Terra, 2014.

HÖFFE, O.. $O$ que é justiça? Porto Alegre: EDIPUCRS, 2003.

LARROSA, J. Experiência e alteridade em educação. Revista Reflexão e Ação, Santa Cruz do Sul, v. 19, n. 2, p. 04-27, jul./dez. 2011.

LÉVINAS, E.. Totalité et infini: essai sur l'extériorité. La Haye: Martinus Nijhoff, 1961.

2002.

. De Deus que vem à ideia. Petrópolis: Vozes, Ética e Infinito. Lisboa: Edições 70, 2014.

PINHEIRO, C. de M. Tolerância e respeito à alteridade em uma educação democrática. In: GUÉRIOS, Etiènne; STOLTZ, Tânia (Org.). Educação e Alteridade. São Carlos: EDUFSCar, 2010, p. 39-48.

SILVA, M. B. da. A Filosofia da Libertação: A partir do contexto histórico-social da América Latina. Roma: Gregoriana, 1998.

\section{Sobre o autor}

Nilo Agostini é Doutor em Teologia pela Universidade de Ciências Humanas de Strasbourg, França, onde obteve também os títulos de Mestrado e de D.E.A. (Diploma de Estudos Aprofundados). Hoje é professor e pesquisador do Programa de Pós-graduação Stricto Sensu em Educação da USF (Universidade São Francisco).

Recebido em março de 2016.

Aprovado em abril de 2016. 